\title{
On the seasonal variations of ocean bottom pressure in the world oceans
}

\author{
Xuhua Cheng ${ }^{1,2^{*}}\left(\mathbb{D}\right.$, Niansen Ou ${ }^{3}$, Jiajia Chen ${ }^{1}$ and Rui Xin Huang ${ }^{4}$
}

\begin{abstract}
Seasonal variability of the ocean bottom pressure (OBP) in the world oceans is investigated using 15 years of GRACE observations and a Pressure Coordinate Ocean Model (PCOM). In boreal winter, negative OBP anomalies appear in the northern North Pacific, subtropical South Pacific and north of $40^{\circ} \mathrm{S}$ in the Indian Ocean, while OBP anomaly in the Southern Ocean is positive. The summer pattern is opposite to that in winter. The centers of positive (negative) OBP signals have a good coherence with the mass convergence/divergence due to Ekman transport, indicating the importance of wind forcing. The PCOM model reproduces the observed OBP quite well. Sensitivity experiments indicate that wind forcing dominates the regional OBP seasonal variations, while the contributions due to heat flux and freshwater flux are unimportant. Experiments with daily sea level pressure (SLP) forcing suggest that at high frequencies the non-static effect of SLP is not negligible.
\end{abstract}

Keywords: Ocean bottom pressure, Sea level, PCOM, GRACE

\section{Introduction}

Sea level changes in global and regional oceans and their causes are the subjects of intense debate (e.g., Levitus et al. 2000; Cabanes et al. 2001; Church et al. 2001; Antonov et al. 2002; Munk 2002; 2003; Cazenave and Nerem 2004; Lombard et al. 2005; Carton et al. 2005; Ishii et al. 2006; Hay et al. 2015; Chambers et al. 2017; Dangendorf et al. 2017; Frederikse et al. 2020). Sea level rise during the twentieth century has been estimated at 1.5 to $2 \mathrm{~mm}$ /year from tide gauges (Gornitz et al. 1995; Douglas et al. 2001; Church et al. 2004). Recent studies in the last few years show that the number was very probably lower, somewhere between 1.1 and $1.2 \mathrm{~mm}$ /year before 1990 (Hay et al. 2015; Dangendorf et al. 2017). The main causes of this rise are changes in oceanic mass (glacial melting and other continental storage) and in thermal expansion of water induced by global warming.

\footnotetext{
*Correspondence: xuhuacheng@hhu.edu.cn

${ }^{1}$ College of Oceanography, Hohai University, 1 Xikang Road,

Nanjing 210098, China

Full list of author information is available at the end of the article
}

Based on the historical archive of temperature and salinity data, Antonov et al. (2002) showed that an increase of sea water temperature (thermosteric sea level) gave rise to a global sea level increase of $0.5 \mathrm{~mm} /$ year. The physical meaning of the halosteric sea level rise was clearly explained by Munk (2003). Based on mass conservation, instead of volume conservation approximation used in the traditional definition of halosteric rise, Munk (2003) demonstrated that the halosteric sea level rise based on the volume conservation approximation should be multiplied by a factor of 36.7 to reflect the contribution related to the eustatic rise (increase in mass). These two studies suggested that in the twentieth century eustatic rise contributed to sea level rise more than ocean warming. Based on altimetry, Argo and GRACE data, Chambers et al. (2017) also suggested that the ocean bottom pressure (OBP) trend accounts for $69 \%$ sea level rise over 2005-2014, indicating the importance of changes in the ocean mass.

Before the launching of GRACE, studies of OBP were mainly based on theoretical diagnosis and numerical models due to the lack of observations. Gill and Niller (1973) pioneered the study of OBP; they derived the
SpringerOpen

(c) The Author(s) 2021. Open Access This article is licensed under a Creative Commons Attribution 4.0 International License, which permits use, sharing, adaptation, distribution and reproduction in any medium or format, as long as you give appropriate credit to the original author(s) and the source, provide a link to the Creative Commons licence, and indicate if changes were made. The images or other third party material in this article are included in the article's Creative Commons licence, unless indicated otherwise in a credit line to the material. If material is not included in the article's Creative Commons licence and your intended use is not permitted by statutory regulation or exceeds the permitted use, you will need to obtain permission directly from the copyright holder. To view a copy of this licence, visit http://creativecommons.org/licenses/by/4.0/. 
equation of $\mathrm{OBP}$ and diagnosed the seasonal distribution of OBP in the northern Pacific and northern Atlantic. They pointed out that the OBP represents the barotropic response to changes in the wind stress, which dominates the variations of sea level at high latitudes. Wunsch and Stammer (1997) reviewed the oceanic response to the atmospheric pressure loads. Besides the static response (inverted barometer effect), non-static response occurs at certain periods in some regions (Ponte et al. 1991; Ponte 1992, 1993; Gaspar and Ponte 1997), indicating that the variations of sea level pressure (SLP) may alter the OBP. Ponte (1999) firstly simulated the seasonal variability of OBP using a volume conserved model. The model results indicated that seasonal amplitude of largescale OBP ranges from less than $1 \mathrm{~cm}$ to several centimeters in shallow water and continental shelf. Huang et al. (2001) developed the first model in pressure coordinates, the Pressure Coordinates Ocean Model (PCOM), which exactly conserves the total mass. They found the evolution of free surface elevation and bottom pressure in the model is different from that produced by models based on the Boussinesq approximations (Huang and Jin 2002). Due to limited observations, these diagnostic and model results have not yet been verified.

The launch of GRACE (Gravity Recovery and Climate Experiment) in 2002 opened up a new horizon because it provides an entirely new tool for monitoring OBP changes in the world oceans (Tapley et al. 2004; Wahr et al. 2004; Chamber 2006). Based on GRACE data collected over a relatively short time and oceanic models (mostly volumetric conservation models), earlier studies were mainly focused on the seasonal variability of OBP. These studies show that large annual amplitude of OBP is located at high-latitudes and along coastal regions, typically reaching $4-5 \mathrm{~cm}$ (Tapley et al. 2004; Wahr et al. 2004; Kanzow et al. 2005; Ponte et al. 2007; Chambers and Schroter 2011; Cheng et al. 2010; Song and Colberg 2011; Piecuch and Ponte 2014; Wang et al. 2015; PeraltaFerriz et al. 2017). Compared with signals in sea level, the amplitude of OBP is relatively small in the western boundary currents and the Southern Ocean, where the annual amplitude of sea level often exceeds $30 \mathrm{~cm}$.

As the record of GRACE data extended, a number of studies found that interannual variations of OBP explain a significant part of total sea level signals in several regions, such as the northwestern Pacific, South Pacific, northeast Atlantic, South Indian Ocean and continental shelf (e.g., Chambers and Willis 2009; Chambers 2011; Cheng et al. 2013; Johnson and Chambers 2013; Piecuch et al. 2013; Ponte and Piecuch 2014; Wang et al. 2015; Liau and Chao 2017). On decadal time scales, the OBP trend dominates sea level rise in the North Pacific during the GRACE period, which is linked to decadal wind stress variations associated with the Pacific Decadal Oscillation (Chambers 2011; Cheng et al. 2013). In the Southern Oceans, the variations of OBP are also related to fluctuations of wind. During 2003-2012, the weakening of zonal wind accounts for the increase trend of OBP in the Southern Indian Ocean and Southern Atlantic, while the decrease of OBP in the Southern Pacific is associated with enhancement of wind field (Makowski et al. 2015).

Besides satellite and hydrographic observations, numerical models can also serve as good tools for the study of sea level variations and correlative physical processes. However, most currently used models are based on the Boussinesq approximations (e.g., Ponte 1999; Ponte et al. 2007; Bingham and Hughes 2008; Köhl et al. 2012; Kuhlmann et al. 2013; Poropat et al. 2018; Androsov et al. 2020); such models cannot properly represent the OBP changes associated with thermal expansion or contraction. Surface heating gives rise to decline of bottom pressure in the Boussinesq models; while in a mass-conserving model surface heating/cooling does not directly change bottom pressure. Similarly, the response to precipitation is also incorrectly simulated in the Boussinesq models (Huang et al. 2001; Huang and Jin 2002). Therefore, in the currently used models based on the Boussinesq approximations, a conversion from the volume conservation to the mass conservation is required (Greatbatch 1994; Huang and Jin 2002; Losch et al. 2004; Wunsch et al. 2007; Song et al. 2011). Mass-conserving models can predict sea level change more accurately. In particular, with data assimilation, eustatic height change can be inferred from data assimilation of salinity and bottom pressure.

Many studies had revealed the seasonal-to-decadal variability of OBP and its contribution to sea level change; however, the patterns and mechanisms of regional OBP have not been sufficiently studied. Most model studies on OBP are based on volume-conserving models. A massconserving model is needed to correctly represent the physical processes related to OBP and sea level change. More than 15-year synchronous GRACE, Argo and altimetry data are now available, which can be used to verify the results obtained from previous theoretical and numerical studies.

In this study, we first examine the seasonal distribution of OBP in the world oceans based on 15-year GRACE data. Second, OBP forced by wind stress is diagnosed using equations in Gill and Niiler (1973). Finally, a non-Boussinesq model, the Pressure Coordinates Oceanic Model (PCOM), is used to simulate the variations of OBP. The rest part of this paper is organized as follows. Section "Data, analyses, and model" describes the observational datasets, methods and models used 
for the analysis. Section "Results" presents the seasonal variability of OBP, as well as the physical mechanisms. Section "Summary and discussion" is the summary and discussion.

\section{Data, analyses, and model Data sets}

The monthly sea-level anomaly (SLA) data used in this study are taken from the multi-satellite convergence sea level anomaly data released by the European Copernicus Marine Environment Monitoring Service (CMEMS). The product is available on a $1 / 4^{\circ}$ Mercator grid at monthly intervals and spans a period from 1993 to 2017.

To check the contribution of steric sea level, we use monthly temperature and salinity data from World Ocean Atlas 2009. The product has a $1^{\circ} \times 1^{\circ}$ horizontal resolution and 24 vertical levels from surface to $1500 \mathrm{~m}$ depth.

To reveal the spatial-temporal variations of OBP, we use the monthly GRACE data (CSR Release 06 solutions) from https://podaac.jpl.nasa.gov/GRACE. The data, on a spatial grid $1^{\circ} \times 1^{\circ}$, are spatially smoothed with a $500-\mathrm{km}$ Gaussian smoothing and spans the period from August 2002 to December 2016.

To diagnose OBP, we use monthly surface wind stress derived from ERA-Interim (ERA-I) surface wind-speed data from the European Centre for Medium-Range Weather Forecasts (ECMWF) product, which is available on a $0.75^{\circ} \times 0.75^{\circ}$ grid for the period 1979-2015 (Dee et al. 2011; http://www.ecmwf.int/products/data/archi ve/).

\section{Equation for the bottom pressure}

The OBP changes are due to the variability in wind stress, surface heat and freshwater fluxes, plus melting of landbased glaciers. The contribution due to wind stress variability reflects the barotropic response of ocean to wind stress. Large-scale motions for time scale longer than the seasonal time scale can be considered approximately quasi-steady. For a steady state the OBP changes can be estimated using the OBP equation by Gill and Niiler (1973):

$$
\left(\mathcal{H}_{1}-\mathcal{H}_{2}\right)\left[p_{b}^{\prime}\left(\lambda_{1}\right)-p_{b}^{\prime}\left(\lambda_{2}\right)\right]=2 \Omega a^{2} \iint_{A} \omega_{E K}^{\prime} \cos \varphi d \varphi d \lambda,
$$

where $\mathcal{H}=H \operatorname{cosec} \varphi, \varphi$ is latitude, $\lambda$ is longitude, $\omega_{E K}^{\prime}$ is Ekman pumping velocity, $p_{b}$ is bottom pressure, $H$ is the depth of the ocean, $a$ is the Earth's radius, $\Omega$ is the Earth rotation rate. The OBP is obtained by integrating over the area $A$ bounded by the longitudes $\lambda=\lambda_{1}$ and $\lambda=\lambda_{2}$ and $\mathcal{H}_{1}=H_{1} \operatorname{cosec} \varphi_{1}$ and $\mathcal{H}_{2}=H_{2} \operatorname{cosec} \varphi_{2}$, which indicates that OBP at certain grid is either forced by local wind or remote forcing from east.

\section{The pressure coordinate ocean model}

The oceanic general circulation model used in this study is the Pressure Coordinate Ocean Model (PCOM), which was originally developed by Huang et al. (2001), and further improved by Zhang et al. (2014). The model has 60 pressure layers. Its horizontal resolution is $1^{\circ} \times 1^{\circ}$. Instead of using a vertical mixing scheme, PCOM adopts a set of climatic dataset of turbulent mixing coefficients calculated by Zhang et al. (2014) based on real energy sources for vertical mixing. See Huang et al. (2001) and Zhang et al. (2014) for more detailed descriptions about the model.

A spin-up run was performed for 600 years from a static state under repeating climatological monthly mean atmospheric forcing. The wind stress vector and SLP were from the National Centers for Environ mental Prediction-National Center for Atmospheric Research (NCAR/NCEP) reanalysis data (Kalnay et al. 1996); heat flux and freshwater flux were from Objectively Analyzed Air-Sea Fluxes (OAFlux) of Woods Hole Oceanographic Institute (http://oaflux.whoi.edu). The initial temperature and salinity for the spin-up run were derived from World Ocean Atlas 2009 (Locarnini et al. 2010). Restarting from the spin-up run, five experiments were carried out for 20 years (Table 1), and the last 10-year model outputs were used to analyze the seasonal variability. To investigate the non-static effect of SLP, three experiments driven by daily atmospheric forcing were also carried out (Table 1).

\section{Results}

\section{Seasonal variability of the observed OBP in the world oceans}

As shown in Fig. 1, OBP has significant seasonal variability. During boreal winter, negative OBP anomalies are located in the northern North Pacific and

Table 1 Setting for experiments

\begin{tabular}{ll}
\hline Exp. 1 & Continue to run for 20 years \\
Exp. 2 & Same as in Exp. 1, heat flux is cut off \\
Exp. 3 & Same as in Exp. 1, freshwater flux is cut off \\
Exp. 4 & Same as in Exp. 1, wind stress is cut off \\
Exp. 5 & Same as in Exp. 1, SLP is cut off \\
Exp. 6 & Same as in Exp. 1, but forced by ECMWF \\
& daily SLP and wind stress from 1990 to \\
Exp. 7 & 2018 \\
Exp. 8 & Same as in Exp. 6, SLP is cut off \\
\hline
\end{tabular}



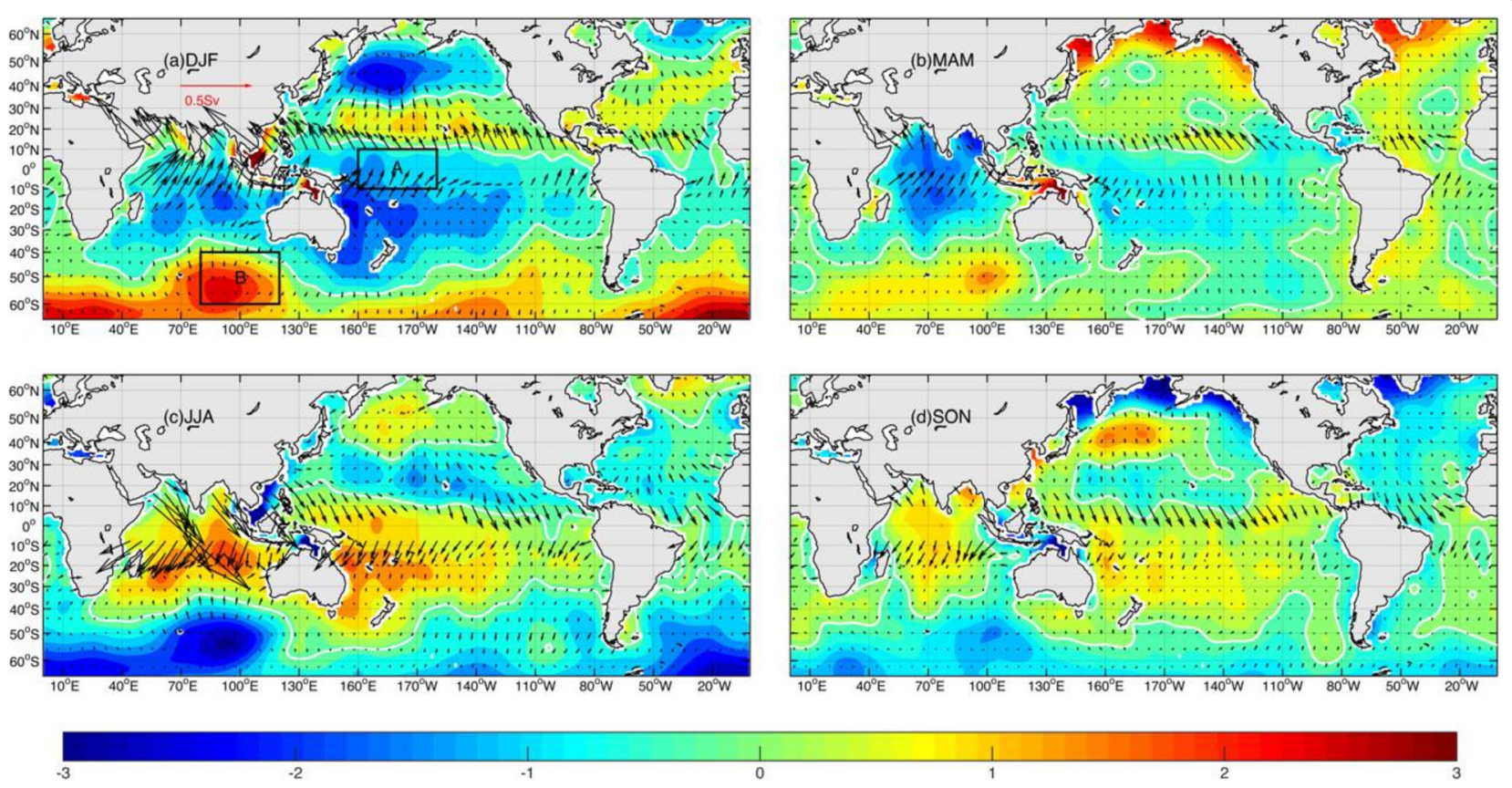

2

Fig. 1 Ocean bottom pressure (color maps, in $\mathrm{cm}$ ) derived from GRACE data and Ekman transport anomalies (vectors, in Sv) in the world oceans for four seasons. The anomalies are relative to their annual mean

subtropical South Pacific, ranging from $-1 \mathrm{~cm}$ to $-3 \mathrm{~cm}$. The vectors represent the Ekman transport anomalies (Sv per grid box). In above two regions, vectors' pattern indicates the local divergence of mass, which accounts for negative anomalies of OBP to some extent. Positive OBP anomalies are found in the subtropical North Pacific, corresponding to the convergence of Ekman transport (Fig. 1a). In the South China Sea (SCS), positive OBP anomalies are located along the western boundary, and this is due to the Ekman transport driven by northeasterly wind during winter (Cheng and Qi 2010). North of $40^{\circ} \mathrm{S}$ in the Indian Ocean, significant divergence is located in the central Indian Ocean, accounting for the negative OBP anomalies. Along the coast of northern Indian Ocean, positive OBP anomalies are caused by the strong onshore Ekman transport. In the North Atlantic Ocean, weak negative OBP anomalies are in the subpolar region, while positive OBP anomalies appear between $10^{\circ} \mathrm{N}$ and $50^{\circ} \mathrm{N}$. In the Southern Ocean, strong positive OBP anomalies $(\sim 3 \mathrm{~cm})$ are located in the southeastern Southern Indian Ocean and Southern Atlantic, corresponding to the convergent southward Ekman transport. The distribution of OBP during boreal spring is similar to that during winter, but somewhat weaker. The remarkable differences are the positive anomalies in the subpolar Pacific and Atlantic (Fig. 1b). During boreal summer (autumn), overall the wind direction is flipped, and the OBP pattern is opposite to that during winter (spring) (Fig. 1c and d).

Based on GRACE observations and numeric models, numerous studies have investigated seasonal variations of OBP in global ocean, with a particular focus on the North Pacific (e.g., Gill and Niiler 1973; Ponte 1999; Kanzow et al. 2005; Bingham and Hughes 2008; Ponte et al. 2007; Chambers 2011; Johnson and Chambers 2013; Piecuch and Ponte 2014; Piecuch et al. 2015). The seasonal distribution of OBP revealed in this study are similar to that of previous studies. Using longer timeseries of data, we can obtain more robust seasonal cycle. Furthermore, Fig. 1 illustrates the relation between OBP and Ekman transport more intuitively.

Figure 2a shows the annual cycle of sea level, steric sea level and OBP anomalies in the western tropical Pacific $\left(160^{\circ}-200^{\circ} \mathrm{E}, 10^{\circ} \mathrm{S}-10^{\circ} \mathrm{N}\right.$, Box A in Fig. 1a). Sea level has significant seasonal variability, reaching the maximum during boreal winter $(2 \mathrm{~cm})$ and minimum during boreal summer $(-3 \mathrm{~cm})$. Steric sea level has an annual cycle similar to sea level, while the OBP has an opposite phase. Thus, in this region steric sea level dominates the sea level variations, indicating the importance of baroclinic processes at low latitudes. In western tropical Pacific, sea level anomaly is quite larger than the sum of steric and OBP anomalies. The unclosed sea level budget is likely due to the errors exist in observations. In the southeastern South Indian Ocean $\left(80^{\circ}-120^{\circ} \mathrm{E}, 60^{\circ}-40^{\circ} \mathrm{S}\right.$, Box B in 

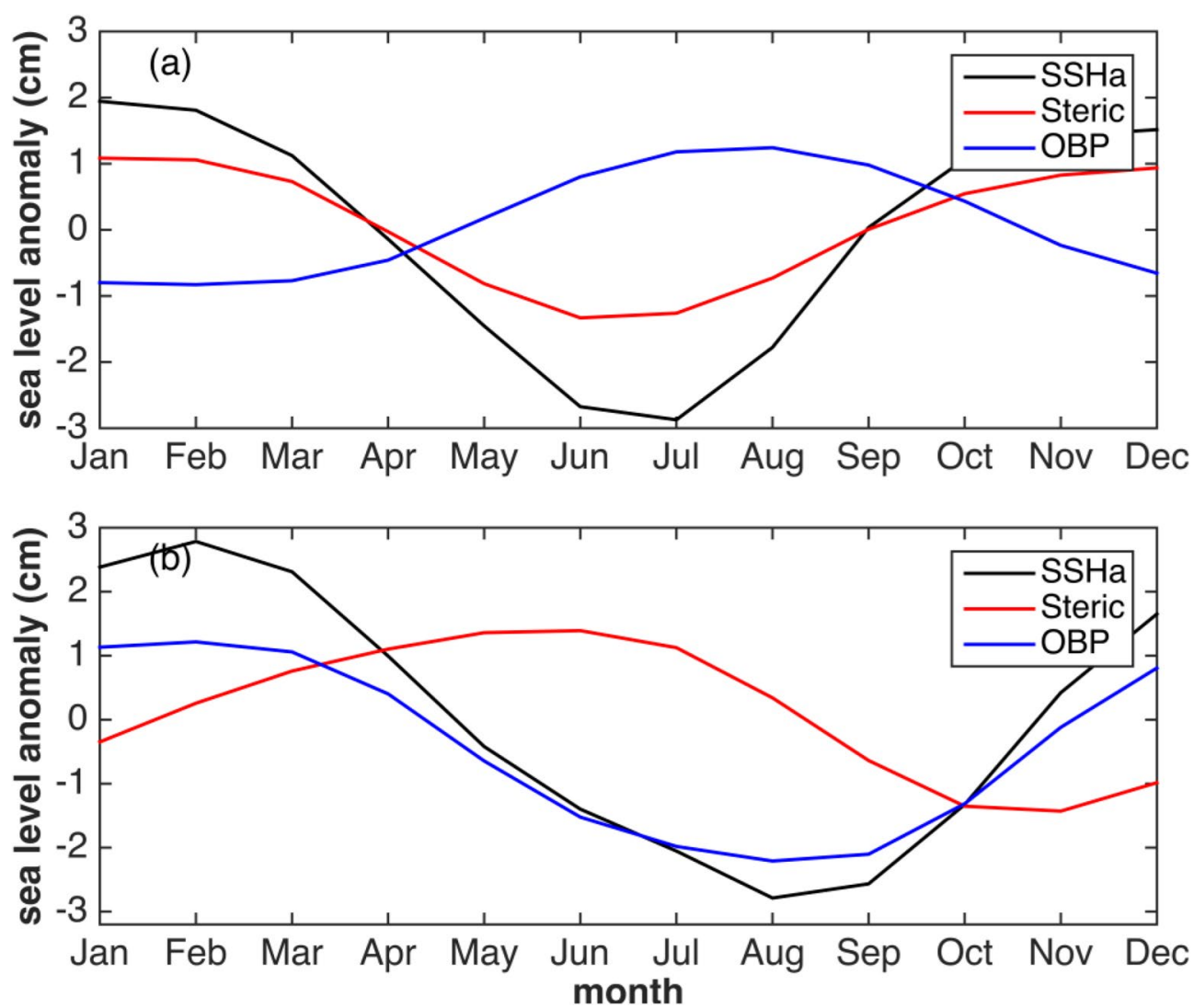

Fig. 2 a Annual cycle of sea level, steric sea level and ocean bottom pressure anomalies ( $\mathrm{cm}$ ) averaged in the tropical western Pacific $\left(160^{\circ}-200^{\circ} \mathrm{E}\right.$, $10 \mathrm{~S}^{\circ}-10^{\circ} \mathrm{N}, \mathrm{Box} \mathrm{A}$ in Fig. 1a), $\mathbf{b}$ same as $\mathbf{a}$ but for anomalies in the southeastern southern Indian Ocean $\left(80^{\circ}-120^{\circ} \mathrm{E}, 60^{\circ}-40^{\circ} \mathrm{S}, \mathrm{Box} \mathrm{B}\right.$ in Fig. $\left.1 \mathrm{a}\right)$

Fig. 1a), sea level has stronger positive (negative) anomaly during February-Apirl (July-September). The seasonal cycle of OBP anomaly is quite similar to that of sea level anomaly, while the seasonal cycle of steric sea level is different (Fig. 2b). This figure suggests that OBP dominates the sea level variations, indicating the important role of barotropic processes at high latitudes.

\section{Diagnostic OBP}

As shown in Fig. 1, OBP anomalies are closely linked to the Ekman transport divergence/convergence. Figure 3 shows the observed OBP and diagnosed OBP based on Eq. (1) in the North Pacific (Gill and Niiler 1973). Overall, the pattern and amplitude of the signals obtained from these two approaches are similar, especially for the large-scale feature in the open northern North Pacific during boreal winter (summer) (Fig. 3). However, the results from the diagnostic equation are different from observations in the regions with complicated bottom topography. When there exists closed contour of $\mathcal{H}$, such as in the southern Indian Ocean and Pacific, the OBP cannot be obtained by integration along $\mathcal{H}$ from eastern boundary. Under this circumstance, Eq. (1) will be invalid. At lower latitudes and longer periods, baroclinic processes also make considerable contributions to the OBP variations (Piecuch 2013,2015; Piecuch and Ponte 2014; Piecuch et al. 2015). In addition, the OBP adjusts around the world oceans. Therefore, to fully understand OBP variations, even on regional scale, a global model is needed.

\section{Simulated OBP from PCOM model}

Figure 4 shows the OBP anomalies in boreal winter and summer simulated by PCOM (Exp. 1). The model reproduces the observed OBP pattern quite well; for example, the OBP dipole in the North Pacific, South Pacific and Indian Oceans. Even in the marginal seas, such as the South China Sea and Gulf of Carpentaria, the OBP signal reversion in summer and winter are also simulated in the model. In the tropical western Pacific (Region A) and southeastern South Indian Ocean (Region B), the annual cycle of OBP, sea level and steric anomalies simulated by the model are quite similar to the observations (Figs. 2 and 5) and results based on volume-conserving models 

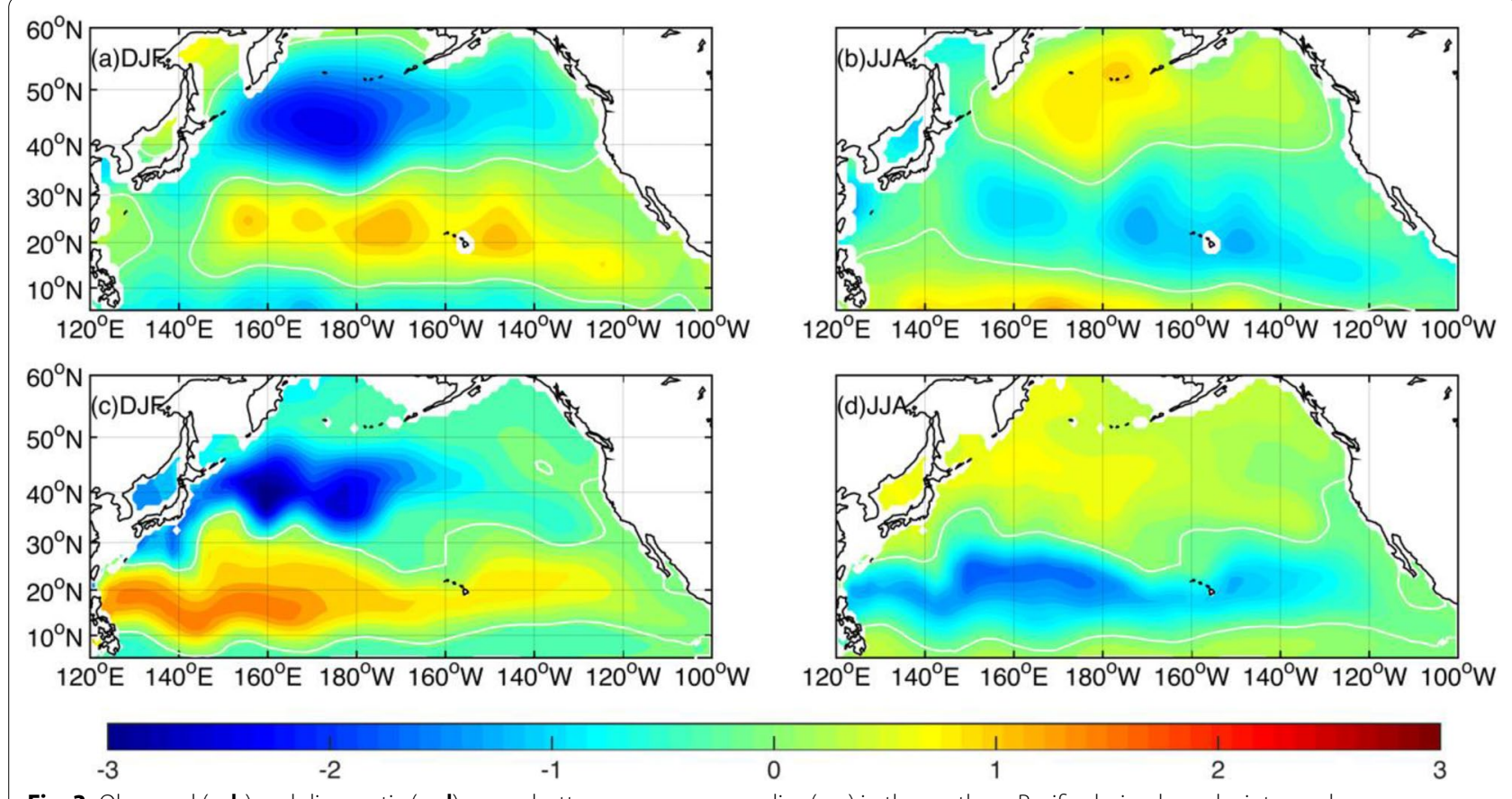

$-2$

$-1$

1

2

Fig. 3 Observed $(\mathbf{a}, \mathbf{b})$ and diagnostic $(\mathbf{c}, \mathbf{d})$ ocean bottom pressure anomalies $(\mathrm{cm})$ in the northern Pacific during boreal winter and summer

(e.g., Ponte 1999; Ponte et al. 2007; Bingham and Hughes 2008; Köhl et al. 2012; Kuhlmann et al. 2013; Poropat et al. 2018; Androsov et al. 2020). Figures 4 and 5 indicate that the PCOM can simulate the seasonal cycle of regional OBP quite well; thus, this model can be used to study the dynamics of OBP variability.

\section{Dynamics of seasonal variability of OBP}

To explore the importance of each forcing, we carried out another four experiments (Exps. 2-5 in Table 1). There is no significant difference between results from Exp. 1 and Exp. 2 (Fig. 6a). As discussed by Huang and Jin (2001), heating creates no barotropic pressure signals; thus, local heating does not lead to OBP signals initially. However, nonuniform heating has an impact on the ocean circulation, and then causes slight mass redistribution in some regions indirectly. Overall, heat flux forcing is not important for the seasonal variability of OBP. The freshwater flux is tuned off in Exp. 3, the OBP pattern remains quite similar to that in Exp. 1 (Fig. 6b). Although precipitation can induce OBP signals, the horizontal scales of precipitation events are much smaller than the barotropic radius of deformation. As a result, the corresponding signals are mostly dispersed to the other parts of the world oceans, with negligible residuals left behind (Huang and Jin, 2002). Therefore, freshwater flux through precipitation has also little impact on regional bottom pressure.
The contribution to OBP from wind forcing is shown in Fig. 6c (Exp.1-Exp. 4). In the Pacific, Indian Ocean and Southern Ocean, OBP pattern is similar to that in Exp.1 (Fig. 4a), which suggests that wind forcing accounts for the dominant part of the regional OBP pattern observed by GRACE.

If the static effect based on the inverse barometer (IB) approximation is accurate, SLP anomaly should lead to no OBP signals. The difference of Exp. 1-Exp. 5 illustrates the contribution due to the non-static effect of SLP (Fig. 6d). The OBP difference in Fig. 6d is near zero in most regions on seasonal timescales, while it is relatively large in marginal seas and near the coasts (Fig. 6d). Sensitive experiments based on PCOM indicate that a model without subjected to the SLP can produce accurate results regarding to seasonal OBP and sea surface elevation in the open oceans; however, to accurately simulate the OBP in marginal seas and near the coasts, the model should include the SLP forcing as the upper boundary condition. Besides wind and SLP forcing, the bottom topography might also play a role in the regions with high STD values.

\section{Non-static effect of the sea level pressure}

Driven by climatological monthly mean atmospheric forcing, Exps. 1-5 cannot simulate the high-frequency variations of OBP. The non-static effect of SLP on the OBP is almost absent in the climatological runs. To check 

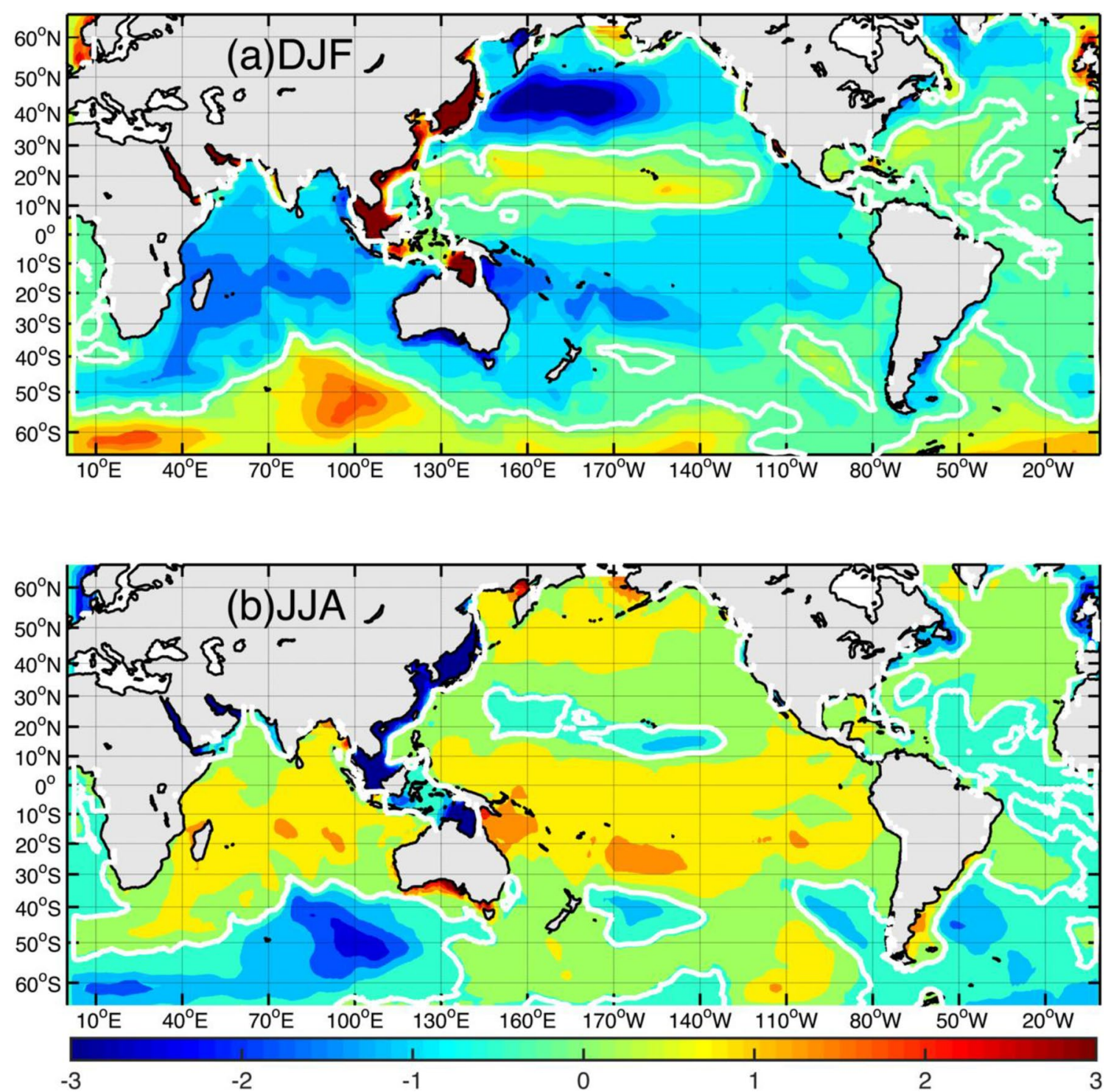

Fig. 4 Simulated ocean bottom pressure anomalies (cm) from PCOM Exp. 1 during boreal winter and summer

impacts of SLP on the high-frequency variations, additional three experiments were carried out by restarting from the spin-up run (Exps. 6-8 in Table 1).

The seasonal pattern of OBP for Exp. 6 is very similar to that for Exp.1, and the winter OBP difference for Exp. 6-Exp. 7 is also very close to that for Exp.1-Exp.5 (figures not shown). In terms of seasonal variations of OBP, almost no difference exists between experiments driven by the climatological monthly mean and the daily atmospheric forcing.

Figure $7 \mathrm{a}$ shows the standard deviation (STD) of OBP with period longer than 30 days for Exp. 6. OBP has strong variability in the north northern Pacific and
Southern Ocean (maximum STD reaches to $5 \mathrm{~cm}$ ). The amplitude and pattern of OBP for Exp.7 is very close to that for Exp. 6 (Fig. 7b). OBP time series at station A $\left(100{ }^{\circ} \mathrm{E}, 50^{\circ} \mathrm{S}\right)$ from Exp. 6 and 7 match very well, with a correlation coefficient of 0.99 (significant above 99\% level). The STD of OBP for Exp. 8 is very small, except for the coastal and shallow water regions, such as the coast of China Sea, Australia, and Antarctica. In these regions, the non-static effect of SLP cannot be neglected (Fig. 7c). Figure 7 indicates that in the open oceans wind forcing dominates the OBP variations with period longer than 30 days, while non-static effect of SLP on OBP can be neglected. 

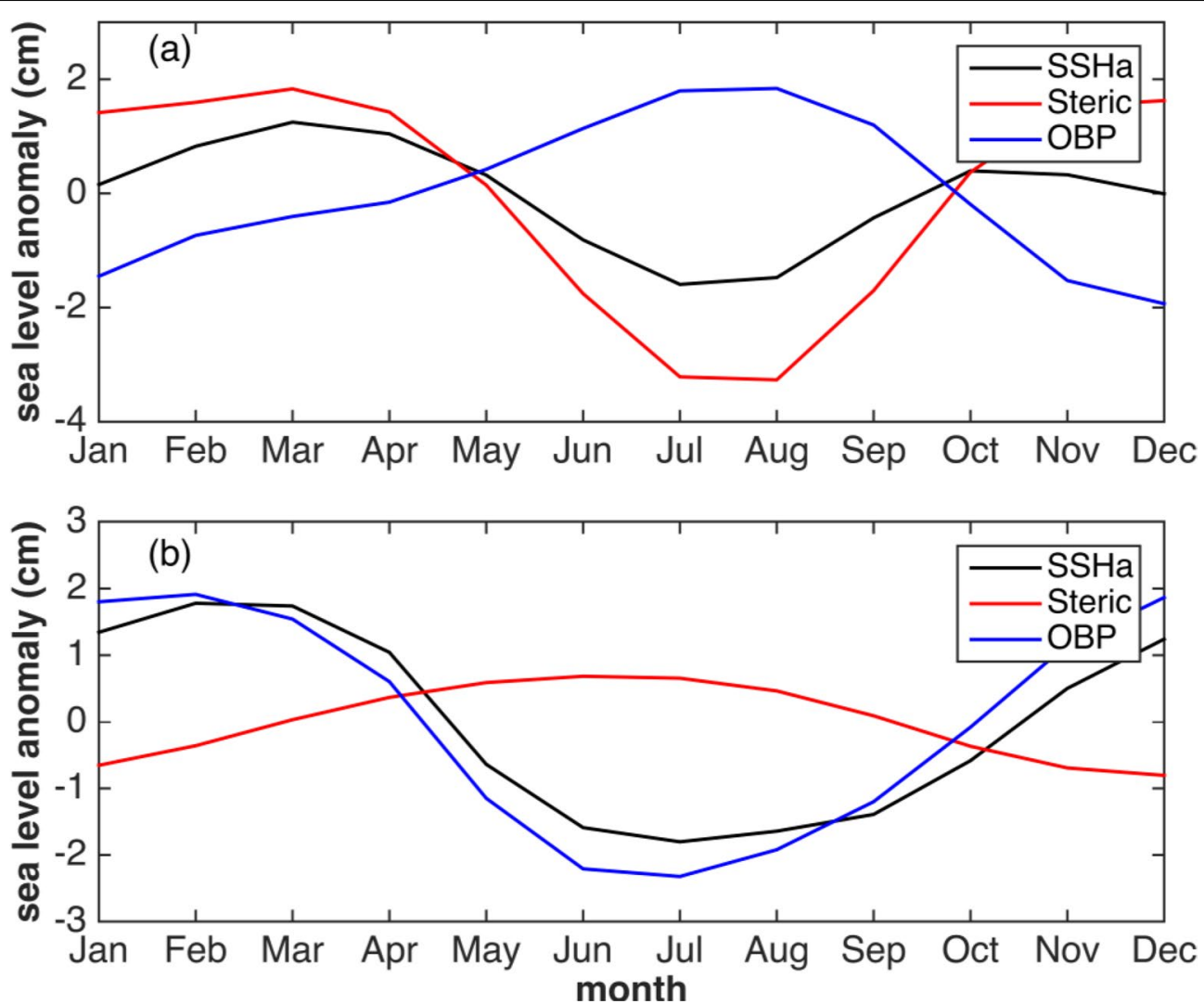

Fig. 5 a Annual cycle of sea level, steric sea level and ocean bottom pressure anomalies from PCOM Exp. 1 averaged in the tropical western Pacific $\left(160^{\circ}-200^{\circ} \mathrm{E}, 10 \mathrm{~S}^{\circ}-10^{\circ} \mathrm{N}\right)$, b same as a but for anomalies in the southeastern southern Indian Ocean $\left(80^{\circ}-120^{\circ} \mathrm{E}, 60^{\circ}-40^{\circ} \mathrm{S}\right)$
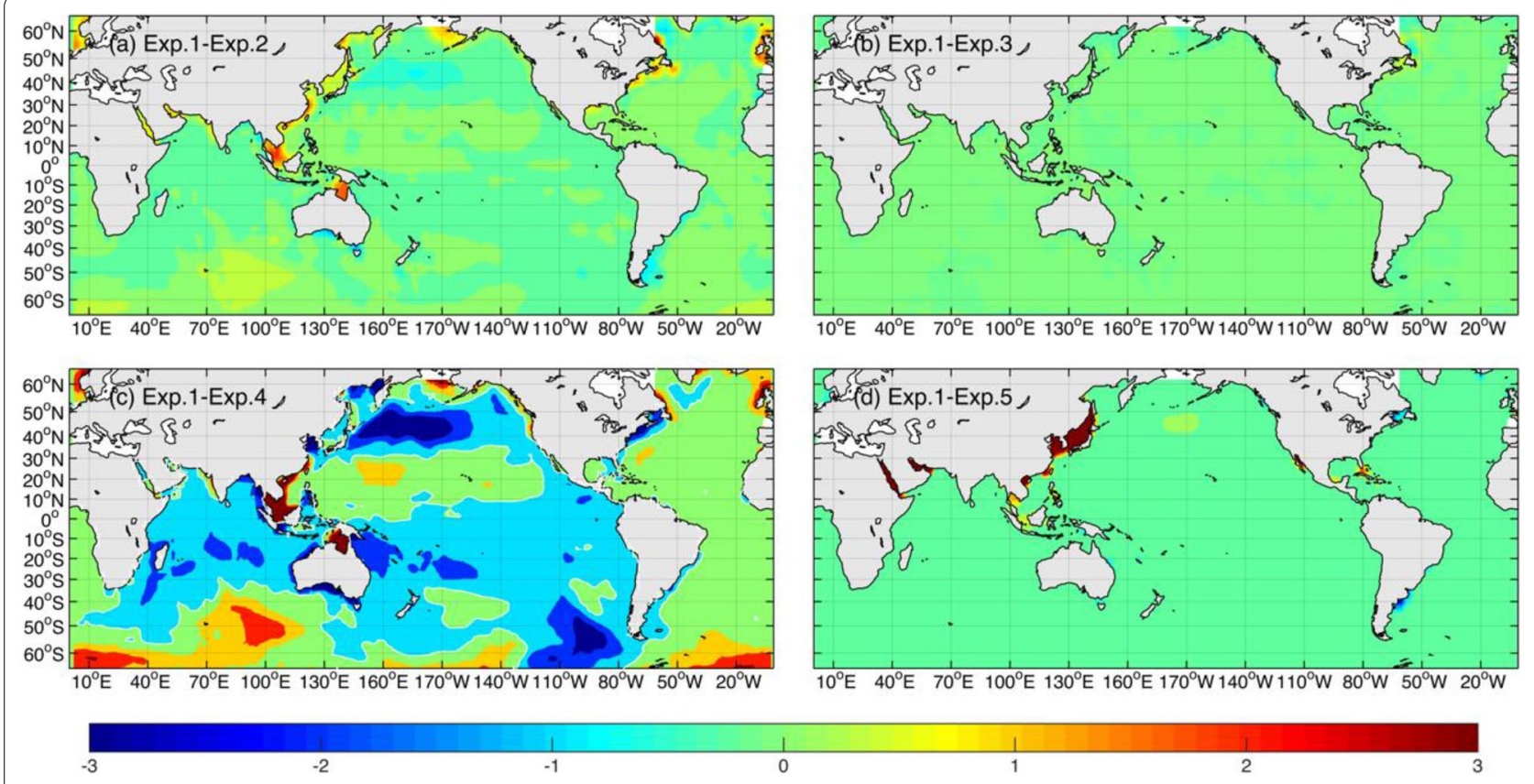

$-2$

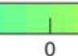

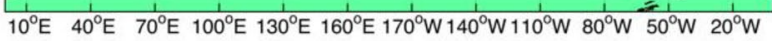

Fig. 6 Simulated ocean bottom pressure anomalies (cm) during boreal winter for a Exp. 1-Exp. 2, b Exp. 1-Exp. 3, c Exp. 1-Exp. 4 and d Exp. 1-Exp. 5 

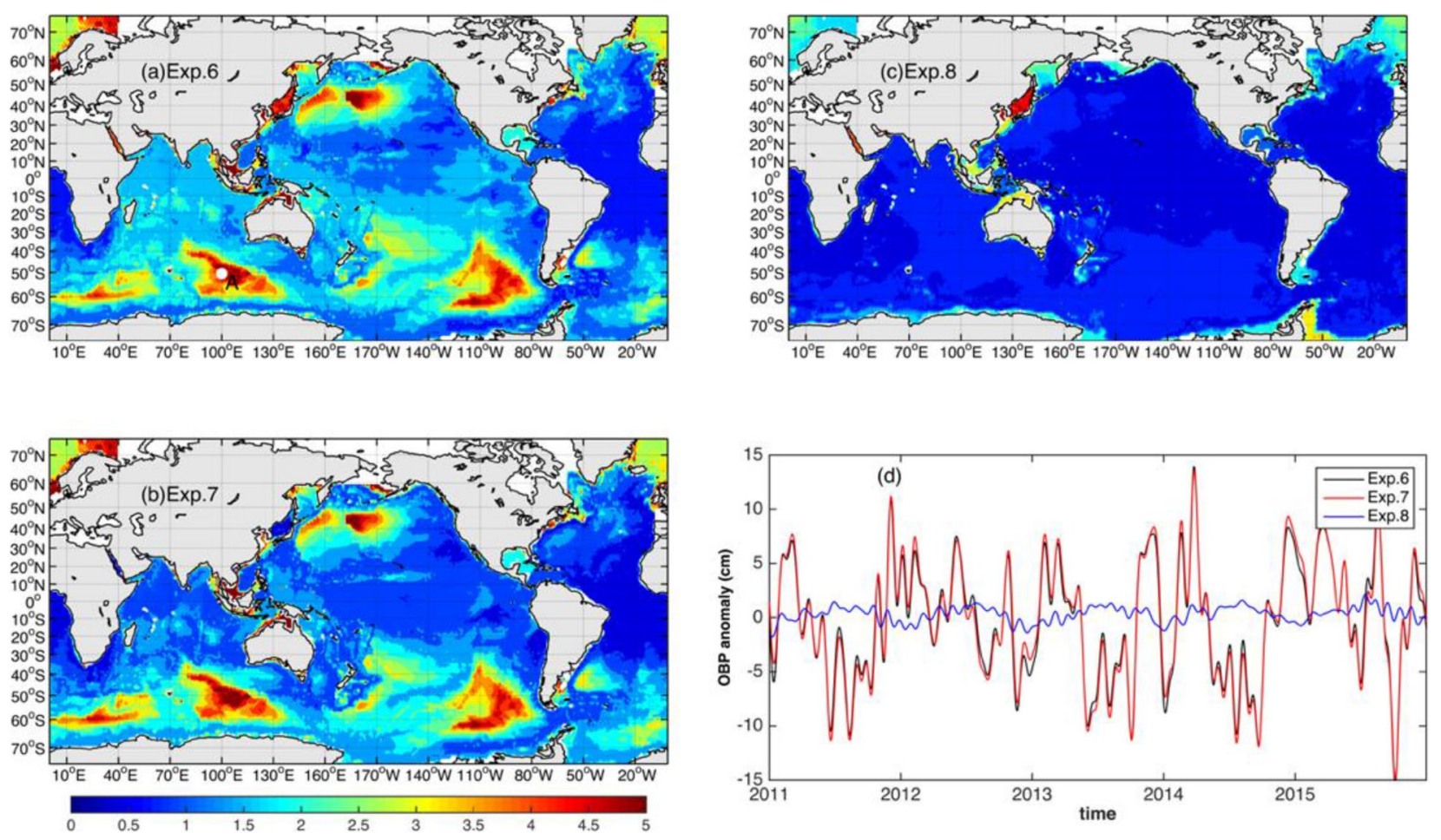

Fig. 7 a Standard deviation (STD, cm) of low-pass-filtered ocean bottom pressure anomalies with period longer than 30 days during 2003-2018 for Exp. 6, b same as a but for Exp. 7, c same as a but for Exp. 8, d ocean bottom pressure time series at point A during 2011-2015 for Exp. 6 (black curve), Exp. 7 (red curve) and Exp.8 (blue curve). Station A in Fig. $7 \mathrm{a}$ is located at $\left(100^{\circ} \mathrm{E}, 50^{\circ} \mathrm{S}\right.$ )

To examine the OBP characters on the synoptic time scale, we analyze the STD of OBP with period shorter than 10 days for Exp. 6 (Fig. 8). High variance is located in the northern Pacific, northern Atlantic and the Southern Ocean (maximum STD reaches to $5 \mathrm{~cm}$ ). The synoptic OBP variance accounts for a considerable part of the total OBP variance in the Southern Ocean. In the Antarctic Circumpolar Current (ACC) area, the strong OBP variance is related to resonance characteristics of the bathymetry at those periods (Poropat et al. 2018). Without SLP forcing, the OBP variance for Exp. 7 is weaker than that for Exp. 6 (Fig. 8a and b).

The difference between Exp. 6 and Exp. 7 is due to SLP forcing. As shown in Fig. 8c, the non-static effect of SLP is remarkable in the northern north Pacific, north western Atlantic and the Southern Ocean. The maximum STD of OBP forced by SLP is on the order of $3 \mathrm{~cm}$ in the southern Pacific, about half of the total variance (Fig. 8a and c). If the horizontal scales of initial perturbations are comparable to the barotropic radius of deformation, the initial pressure perturbations will be retained (Huang and Jin 2002). In the Southern Ocean, the spatial scale of SLP anomaly is on the order of thousands of kilometers, which is comparable with the barotropic Rossby radius of deformation. Therefore, the high-frequency SLP variance can affect the OBP. The phases of OBP time series at station A obtained from Exp. 6 and Exp.7 also match very well, with a correlation coefficient of 0.91 (significant above 99\% level). The STD of OBP time series at station A is about $4.2 \mathrm{~cm}$ for Exp. 6 and $1.9 \mathrm{~cm}$ for Exp.8 (about $45 \%$ of the former). The differences among Exps. 6-8 indicate that the validity of IB correction is dependent on frequency and geographical location (Ponte et al. 1991; Ponte 1992, 1993). Figure 8 suggests that the non-static effect of SLP cannot be neglected on synoptic timescales.

\section{Summary and discussion}

\section{Summary}

In this study, we analyzed the seasonal variability of regional OBP in the world oceans using GRACE data and a mass-conserving model. In boreal winter, negative OBP anomalies are located in the northern North Pacific, subtropical South Pacific and north of $40^{\circ} \mathrm{S}$ in the Indian Ocean, while there are positive OBP signals in the Southern Oceans. The OBP pattern in summer is opposite to that during winter. The positive (negative) OBP centers correspond to the Ekman transport convergence (divergence); thus, local wind forcing may explain dominant part of the seasonal cycle of OBP. 

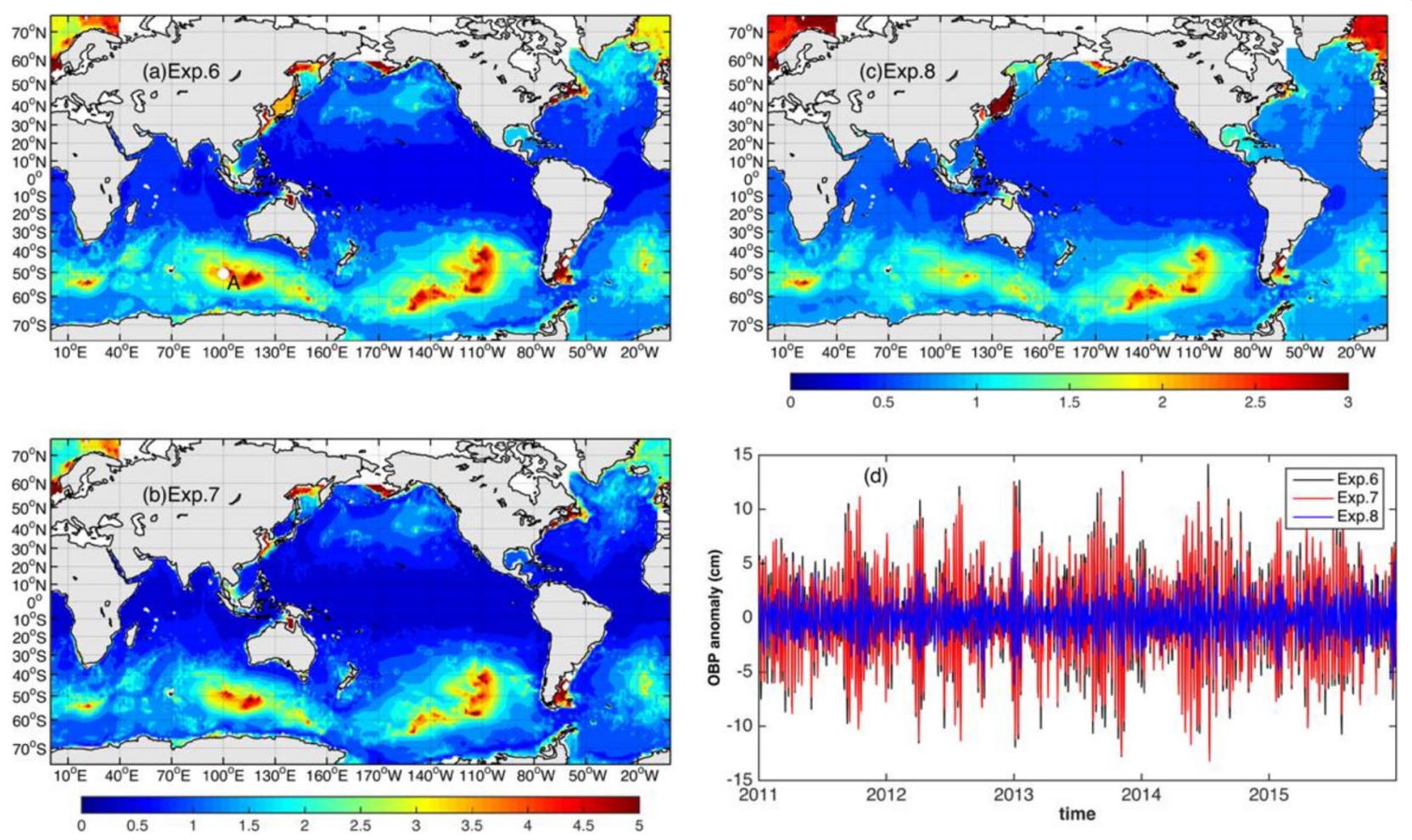

Fig. 8 a Standard deviation (STD, cm) of high-pass-filtered ocean bottom pressure anomalies with period shorter than 10 days during 2003-2018 for Exp. 6, b same as a but for Exp.7, c same as a but for Exp.8, d ocean bottom pressure time series at point A during 2011-2015 for Exp. 6 (black curve), Exp. 7 (red curve) and Exp. 8 (blue curve). Station A in a is located at $\left(100^{\circ} \mathrm{E}, 50^{\circ} \mathrm{S}\right)$

In addition to the local Ekman transport, regional OBP variations are also remotely forced by OBP signals propagating from the eastern basin. Diagnosing OBP using Eq. (1) provides results in good agreement with the observations on seasonal time scales. The OBP adjusts very fast on global scale, hence a global model is needed to fully understand OBP variations, even on regional scale. The PCOM model reproduces the observed OBP quite well, in terms of pattern and amplitude. Sensitivity experiments indicate that wind forcing dominates the regional OBP seasonal variations, while the contribution of heat and freshwater flux is not important.

\section{Discussion}

This study indicates that using IB correction to remove the atmospheric loading on the SSH/OBP is accurate in most regions on seasonal timescales, while the non-static effect can be found in the marginal seas and near coasts. The results of sensitive experiments based on daily SLP forcing indicate that non-static effect of SLP is significant on synoptic timescales in the ocean. Thus, to accurately simulate the high-frequency variations of OBP, the SLP must be used as one of the upper boundary conditions, in addition to the wind stress forcing (Ponte et al. 1991; Ponte 1992, 1993).

So far, the impact of land ice melting and river run-off on the OBP and sea level is not included in the PCOM simulations, although these processes must affect the annual cycle of global mean OBP. Even without polar processes and river run-off, the PCOM reproduces the regional OBP and sea level change reasonably well, indicating the importance of regional ocean dynamic processes. In the near future, the interannual-to-multidecadal variability of global and regional OBP should be studied using the PCOM including the polar processes and land water effects.

\section{Acknowledgements}

This research was supported by the National Key R\&D Program of China (2018YFA0605702), Natural Science Foundation of China (Grant nos. 41522601, 41876002, 41876224).

\section{Authors' contributions}

XC initiated the idea of this study and wrote the manuscript. Other authors contributed to the data analysis and running PCOM model. All authors read and approved the final manuscript.

\section{Availability of data and materials}

Sea level data used in this study were downloaded from the European Copernicus Marine Environment Monitoring Service (CMEMS, https://marine. copernicus.eu); World Ocean Dataset 2009(WOA09) is downloaded from 
http://www.nodcnoaa.gov; ERA-Interim (ERA-l) surface wind-speed data from the European Centre for Medium-Range Weather Forecasts (ECMWF) product were obtained from http://www.ecmwfint/products/data/archive/; monthly GRACE data were obtained from https://podaac.jpl.nasa.gov/GRACE.

\section{Declarations}

\section{Competing interests}

The authors declare that they have no competing interests.

\section{Author details}

${ }^{1}$ College of Oceanography, Hohai University, 1 Xikang Road, Nanjing 210098, China. ${ }^{2}$ Southern Marine Science and Engineering Guangdong Laboratory (Zhuhai), Zhuhai, China. ${ }^{3}$ College of Ocean and Meteorology, Guangdong Ocean University, Zhanjiang, China. ${ }^{4}$ Woods Hole Oceanographic Institution, Woods Hole, Falmouth, MA 02543, USA.

Received: 21 August 2021 Accepted: 24 September 2021 Published online: 12 October 2021

\section{References}

Androsov A, Boebel O, Schröter J, Danilov S, Macrander A, Ivanciu I (2020) Ocean bottom pressure variability: can it be reliably modeled? J Geophys Res Oceans. https://doi.org/10.1029/2019JC015469

Antonov JI, Levitus S, Boyer TP (2002) Steric sea level variations during 1957-1994: importance of salinity. J Geophys Res Oceans. https://doi.org/ 10.1029/2001JC000964

Bingham RJ, Hughes CW (2008) The relationship between sea-level and bottom pressure variability in an eddy permitting ocean model. Geophys Res Lett. https://doi.org/10.1029/2007GL032662

Cabanes C, Cazenave A, LeProvost C (2001) Sea level rise during past 40 years determined from satellite and in situ observations. Science 294:840-842

Carton JA, Giese BS, Grodsky SA (2005) Sea level rise and the warming of the oceans in the Simple Ocean Data Assimilation (SODA) ocean reanalysis. J Geophys Res. https://doi.org/10.1029/2004JC002817

Cazenave A, Nerem RS (2004) Present-day sea level change: observations and causes. Rev Geophys. https://doi.org/10.1029/2003RG000139

Chambers DP (2006) Evaluation of New GRACE Time-Variable Gravity Data over the Ocean. Geophys Res Lett 33(17):LI7603

Chambers DP (2011) ENSO-correlated fluctuations in ocean bottom pressure and wind-stress curl in the North Pacific. Ocean Sci 7:685-692. https:// doi.org/10.5194/os-7-685-2011

Chambers DP, Willis JK (2009) Low-frequency exchange of mass between ocean basins. J Geophys Res. https://doi.org/10.1029/2009JC005518

Chambers DP, Schroter J (2011) Measuring ocean mass variability from satellite gravimetry. J Geodyn. https://doi.org/10.1016/j.jog.2011.04.004

Chambers DP, Cazenave A, Champollion N, Dieng H, Llovel W, Forsberg R, von Schuckmann K, Wada Y (2017) Evaluation of the global mean sea level budget between 1993 and 2014. Surv Geophy 38:309-327. https://doi. org/10.1007/s10712-016-9381-3

Cheng X, Qi Y (2010) On steric and mass-induced contributions to the annual sea-level variations in the South China Sea. Global Planet Change 72(3):227-233. https://doi.org/10.1016/j.gloplacha.2010.05.002

Cheng X, Li L, Du Y, Wang J, Huang RX (2013) Mass-induced sea level change in the northwestern North Pacific and its contribution to total sea level change. Geophys Res Lett. https://doi.org/10.1002/grl.50748

Church JA, Gregory JM, Huybrechts P, Kuhn M, Lambeck K, Nhuan MT, Qin D, Woodworth PL (2001) Changes in Sea Level, in Climate change 2001: the Scientific Basis, edited by J.T. Houghton., pp. 583-638, Cambridge Univ. Press, New York, 639-694

Church JA, White NJ, Coleman R, Lambeck K, Mitrovica J (2004) Estimates of the regional distribution of sea level rise over the 1950-2000 period. J Climate 17:2609-2625

Dangendorf S, Marcos M, Wöppelmann G, Conrad CP, Frederikse T, Riva R (2017) Reassessment of 20th century global mean sea level rise. Proc Nat Acad Sci USA 114(23):5946-5951. https://doi.org/10.1073/pnas.16160 07114
Dee DP, Uppala SM, Simmons AJ, Berrisford P et al (2011) The ERA-Interim reanalysis: configuration and performance of the data assimilation system. Quart J R Meteor Soc 137:553-597. https://doi.org/10.1002/QJ.828

Douglas BC, Kearney MS, Leatherman SP (2001) Sea level rise: history and consequences. Academic, San Diego, p 232

Frederikse T, Landerer F, Caron L, Adhikari S, Parkes D, Humphrey VW, Dangendorf S, Hogarth P, Zanna L, Cheng L, Wu YH (2020) The causes of sea-level rise since 1900. Nature 584(7821):393-397. https://doi.org/10.1038/ s41586-020-2591-3

Gaspar P, Ponte RM (1997) Relation between sea level and barometric pressure determined from altimeter data and model simulation. J Geophys Res 102:961-971

Gill AE, Niiler PP (1973) The theory of seasonal variability in the ocean. Deep Sea Res 20:141-177

Gornitz V (1995) Monitoring sea level changes. Clim Change 31:515-544

Greatbatch RJ (1994) A note on the representation of steric sea level in models that conserve volume rather than mass. J Geophys Res 99:12767-12771

Hay C, Marrow E et al (2015) Probabilistic reanalysis of twentieth-century sealevel rise. Nature 517:481-484. https://doi.org/10.1038/nature14093

Huang RX, Jin XZ (2002) Sea surface elevation and bottom pressure anomalies due to thermohaline forcing. Part I: isolated perturbations. J Phys Oceanogr 32:2131-2150

Huang RX, Jin XZ, Zhang XH (2001) An oceanic general circulation model in pressure coordinates. Adv Atmos Sci 18:1-22

Ishii M, Kimoto M, Sakamoto K, Iwasaki SI (2006) Steric sea level changes estimated from historical subsurface temperature and salinity analyses. J Oceanogr 62(2):155-170

Johnson GC, Chambers DP (2013) Ocean bottom pressure seasonal cycles and decadal trends from GRACE Release-05: ocean circulation implications. J Geophys Res Oceans 118:4228-4240. https://doi.org/10.1002/jgrc.20307

Kalnay E, Kanamitsu M, Kistler R, Collins W, Deaven D, Gandin L, Iredell M, Saha S, White G, Woollen J, Zhu Y (1996) The NCEP/NCAR 40-year reanalysis project. Bull Am Meteorol Soc 77(3):437-472

Kanzow T, Flechtner F, Chave A, Schmidt R, Schwintzer P, Send U (2005) Seasonal variation of ocean bottom pressure derived from Gravity Recovery and Climate Experiment (GRACE): Local validation and global patterns. J Geophys Res. https://doi.org/10.1029/2004JC002772

Köhl A, Siegismund F, Stammer D (2012) Impact of assimilating bottom pressure anomalies from GRACE on ocean circulation estimates. J Geophys Res. https://doi.org/10.1029/2011JC007623

Kuhlmann J, Dobslaw H, Petrick C, Thomas M (2013) Ocean bottom pressure signals around Southern Africa from in situ measurements, satellite data, and modeling. J Geophys Res Oceans 118:4889-4898. https://doi.org/10. 1002/jgrc.20372

Levitus S, Antonov JI, Boyer TP, Stephens C (2000) Warming of the world ocean. Science 287:2225-2229

Liau JR, Chao BF (2017) Variation of Antarctic circumpolar current and its intensification in relation to the southern annular mode detected in the time-variable gravity signals by GRACE satellite. Earth Planets Space. https://doi.org/10.1186/s40623-017-0678-3

Locarnini RA, Mishonov AV, Antonov Jl, Boyer TP, Garcia HE, Baranova OK, Zweng MM, Johson DR (2010) World Ocean Atlas 2009, Volume 1: Temperature., NOAA Atlas NESDIS 68, U.S. Government Printing Office, Washington, D. C., 184 pp

Lombard A, Cazenave A, Le Traon PY, Ishii M (2005) Contribution of thermal expansion to present-day sea-level change revisited. Global Planet Change 47:1-16

Losch M, Adcroft A, Campin JM (2004) How sensitive are coarse general circulation models to fundamental approximations in the equations of motion? J Phys Oceanogr 34:306-319

Makowski JK, Chambers DP, Bonin JA (2015) Using ocean bottom pressure from the gravity recovery and climate experiment (GRACE) to estimate transport variability in the southern Indian Ocean. J Geophys Res Oceans 120:4245-4259. https://doi.org/10.1002/2014JC010575

Munk W (2002) Twentieth century sea level: an enigma. Proc Nat Acad Sci 99:6550-6555

Munk W (2003) Ocean freshening, sea level rising. Science 300:2041-2043

Peralta-Ferriz C, Landerer FW, Chambers DP, Volkov DL, Llovel W (2017) Remote sensing of bottom pressure from GRACE satellites. US CLIVAR Var 15(2):22-28 
Piecuch CG (2013) Dynamics of satellite-derived interannual ocean bottom pressure variability in the western tropical North Pacific. J Geophys Res Oceans 118:5117-5128. https://doi.org/10.1002/jgrc.20374

Piecuch CG (2015) Bottom-pressure signature of annual baroclinic Rossby waves in the northeast tropical Pacific Ocean. J Geophys Res Oceans 120:2449-2459. https://doi.org/10.1002/2014JC010667

Piecuch CG, Ponte RM (2014) Annual cycle in Southern Tropical Indian Ocean bottom pressure. J Phys Oceanogr 44(6):1605-1613. https://doi.org/10. 1175/JPO-D-13-0277.1

Piecuch CG, Fukumori I, Ponte RM, Wang O (2015) Vertical structure of ocean pressure variations with application to satellite-gravimetric observations. J Atmos Ocean Technol 32:603-613

Ponte RM (1992) The sea level response of a stratified ocean to barometric pressure forcing. J Phys Oceanogr 22:109-113

Ponte RM (1993) Variability in a homogenous global ocean forced by barometric pressure. Dynam Atmos Oceans 18:209-234

Ponte RM (1999) A preliminary model study of the large-scale seasonal cycle in bottom pressure over the global ocean. J Geophys Res 104:1289-1300

Ponte RM, Piechuch CG (2014) Interannual bottom pressure signals in the Australian-Antarctic and Bellingshausen Basins. J Phys Oceanogr 44:1456-1465. https://doi.org/10.1175/JPO-D-13-0223.1

Ponte RM, Salstein DA, Rosen RD (1991) Sea level response to pressure forcing in a barotropic numerical model. J Phys Oceanogr 21:1043-1057

Ponte RM, Quinn KJ, Wunsch C, Heimbach P (2007) A comparison of model and GRACE estimates of the large-scale seasonal cycle in ocean bottom pressure. Geophys Res Lett. https://doi.org/10.1029/2007GL029599

Poropat L, Dobslaw H, Zhang L, Macrander A, Boebel O, Thomas M (2018) Time variations in ocean bottom pressure from a few hours to many years: In situ data, numerical models, and GRACE satellite gravimetry. J Geophys Res Oceans 123:5612-5623. https://doi.org/10.1029/2018JC014108
Song YT, Colberg F (2011) Deep ocean warming assessed from altimeters, Gravity Recovery and Climate Experiment, in situ measurements, and a non-Boussinesq ocean general circulation model. J Geophys Res. https:// doi.org/10.1029/2010JC006601

Song YT, Gross R, Wang X, Zlotnicki V (2011) A non-Boussinesq terrain-following OGCM for oceanographic and geodetic applications. Adv Geosci 18:63-86

Tapley DB, Bettadpur S, Ries JC, Thompson PF, Watkins MM (2004) GRACE measurements of mass variability in the earth system. Science 305:503-505

Wahr J, Swenson S, Zlotnicki V, Velicogna I (2004) Time-variable gravity from GRACE: first results. Geophys Res Lett. https://doi.org/10.1029/2004G L019779

Wang J, Wang J, Cheng X (2015) Mass-induced sea level variations in the Gulf of Carpentaria. J Oceanogr 71(4):449-461. https://doi.org/10.1007/ s10872-015-0304-6

Wunsch C, Stammer D (1997) Atmospheric loading and the oceanic "inverted barometer" effect. Rev Geophys 35(1):79-107

Wunsch C, Ponte R, Heimbach P (2007) Decadal trends in sea level pattern: 1993-2004. J Climate 20:5889-5911

Zhang Y, Lin Y, Huang R (2014) A climatic dataset of ocean vertical turbulent mixing coefficient based on real energy sources. Sci China Earth Sci 57(10):2435-2446

\section{Publisher's Note}

Springer Nature remains neutral with regard to jurisdictional claims in published maps and institutional affiliations.

\section{Submit your manuscript to a SpringerOpen ${ }^{\circ}$ journal and benefit from:}

- Convenient online submission

- Rigorous peer review

- Open access: articles freely available online

- High visibility within the field

- Retaining the copyright to your article

Submit your next manuscript at $\mathbf{s p r i n g e r o p e n . c o m ~}$ 